\title{
O LIVRO DIDÁTICO AO LONGO DO TEMPO: A FORMA DO CONTEÚDO ${ }^{1}$
}

\author{
Neli Klix Freitas², Melissa Haag Rodrigues ${ }^{3}$
}

Palavras-chave: livro didático, mediação, comunicação visual.

Resumo: O presente estudo tem por objetivo lançar um olhar sobre a comunicação visual do livro didático e investigar seu papel mediador na relação entre a criança e o conhecimento. Para isso será apresentado um panorama sobre o histórico do livro didático, seu surgimento e transformações para buscar uma melhor compreensão da relevância do livro tanto no ambiente escolar quanto fora dele.

\section{Introdução}

O livro didático faz parte da cultura e da memória visual de muitas gerações e, ao longo de tantas transformações na sociedade, ele ainda possui uma função relevante para a criança, na missão de atuar como mediador na construção do conhecimento. $O$ meio impresso exige atenção, intenção, pausa e concentração para refletir e compreender a mensagem, diferente do que acontece com outras mídias como a televisão e o rádio, que não necessariamente obrigam o sujeito a parar. O livro, por meio de seu conteúdo, mas também de sua forma, expressa em um projeto gráfico, tem justamente a função de chamar a atenção, provocar a intenção e promover a leitura.

Algumas pesquisas vem sendo realizadas ao longo dos anos sobre o livro didático, sobre os seus mais variados aspectos tais como o pedagógico, o político, o econômico e o cultural. A preocupação em pesquisá-lo leva em conta o fato de que o material didático tem uma importância grande na formação do aluno pelo mero fato de ser, muitas vezes, o único livro com o qual a criança entrará em contato. Ele ainda é um dos instrumentos de aprendizagem mais utilizados e, em muitos casos, o único utilizado em sala de aula no ensino fundamental, quando infelizmente, não há o contato dos alunos com outros materiais e informações de outras fontes.

\footnotetext{
${ }^{1}$ Projeto de pesquisa de mestrado em Arte Visuais: "Imagem e palavra no livro didático: a comunicação visual e seu caráter mediador na relação aluno e conhecimento". CEART-UDESC.

${ }^{2}$ Orientadora, doutora em Psicologia, professora do Departamento de Artes Plásticas (CEART-UDESC).

${ }^{3}$ Mestranda regularmente matriculada no Mestrado em Artes Visuais, turma 2007/2, da Universidade do Estado de Santa Catarina-UDESC, na linha de pesquisa de Ensino das Artes Visuais.
} 
Contudo, o livro didático é considerado o "patinho feio" na sua categoria, sendo que se utiliza, em grande parte, de papel e impressão de baixa qualidade, pois sofre muito o impacto do custo das vendas. Enquanto que, no panorama editorial geral a qualidade da linguagem gráfica tem aumentado, na área de didáticos tem-se nivelado por baixo, pois os editores têm receio de fazer qualquer coisa que envolva algum tipo de risco para as vendas. Outro fator associado à baixa qualidade de sua produção, especialmente a visual, pode ser atribuído ao fato de que não necessitam ser tão atrativos nas prateleiras pois, geralmente, não são comercializados em livrarias. E no caso de serem comprados em livrarias, as pessoas que os procuram não tem o poder de decisão da compra, uma vez que precisam adquiri-lo por imposição de alguma instituição de ensino. No segmento de livros infantis, Farbiarz (2004) esclarece que os editores já observaram a importância do aspecto gráfico e de recursos visuais como determinantes na conquista do público infantil.

\section{Um pouco de história}

O livro didático pode ser definido, conforme Stray, como um produto cultural composto, híbrido, que se encontra no "cruzamento da cultura, da pedagogia, da produção editorial e da sociedade" (1993, p.77-78). No universo escolar atual o livro didático coexiste com diversos outros instrumentos como quadros, mapas, enciclopédias, audiovisuais, softwares didáticos, CD-Rom, Internet, dentre outros, mas ainda assim continua ocupando um papel central.

Sua origem está na cultura escolar, mesmo antes da invenção da imprensa no final do século XV. Na época em que os livros eram raros, os próprios estudantes universitários europeus produziam seus cadernos de textos. Com a imprensa, os livros tornaram-se os primeiros produtos feitos em série e, ao longo do tempo a concepção do livro como "fiel depositário das verdades científicas universais" foi se solidificando (GATTI JÚNIOR, 2004, p.36).

A trajetória para que os livros didáticos, dicionários, obras literárias e livros em Braille chegassem até as escolas brasileiras teve início em 1929, com a criação de um órgão específico para legislar sobre políticas do livro didático, o Instituto Nacional do Livro (INL). Seu objetivo era contribuir para a legitimação do livro didático nacional e, conseqüentemente, auxiliar no aumento de sua produção. $\mathrm{O}$ primeiro passo havia sido dado, mas demorou algum tempo para seguir adiante, pois apenas em 1934, no governo 
do presidente Getúlio Vargas, o INL recebeu suas primeiras atribuições, como editar obras literárias para a formação cultural da população, elaborar uma enciclopédia e um dicionário nacionais e expandir o número de bibliotecas públicas.

Em 1938 o livro didático entrou na pauta do governo quando foi instituída por meio do Decreto-Lei $n^{\circ} 1.006$, de 30/12/38 a Comissão Nacional do Livro Didático (CNLD) que estabelecia a primeira política de legislação para tratar da produção, do controle e da circulação dessas obras. Esta comissão possuía mais a função de controle político-ideológico do que propriamente uma função didática (FREITAG et al., 1989).

Após questionamentos sobre a legitimidade desta comissão, em 1945 o Estado consolidou a legislação sobre as condições de produção, importação e utilização do livro didático, restringindo ao professor a escolha do livro a ser utilizado pelos alunos, conforme definido no art. $5^{\circ}$ do Decreto-Lei ${ }^{\circ}$ 8.460, de 26/12/45.

Em 1966 foi realizado um acordo entre o Ministério da Educação (MEC) e a Agência Norte-Americana para o Desenvolvimento Internacional (USAID) que permitiu a criação da Comissão do Livro Técnico e Livro Didático (COLTED). Esta comissão tinha como objetivo coordenar as ações referentes à produção, edição e distribuição do livro didático, e pretendia distribuir gratuitamente 51 milhões de livros no período de três anos. Em relação a este acordo houve diversas críticas por parte de educadores brasileiros, pois ao MEC e ao SNEL (Sindicato Nacional de Editores de Livros) caberiam apenas responsabilidades de execução e aos órgãos técnicos da USAID todo o controle.

Em 1971 com a extinção da COLTED e o término do convênio MEC/USAID, o INL passou a desenvolver o Programa do Livro Didático para o Ensino Fundamental (PLIDEF), assumindo as atribuições administrativas e de gerenciamento dos recursos financeiros.

Cinco anos depois, em 1976, o INL foi extinto e a Fundação Nacional do Material Escolar (FENAME) tornou-se responsável pela execução do PLIDEF. Por meio do decreto $\mathrm{n}^{\mathrm{o}} 77.107$, de 4/2/76 o governo iniciou a compra dos livros com recursos do Fundo Nacional de Desenvolvimento da Educação (FNDE) e com as contribuições dos estados. Porém os recursos não foram suficientes para atender todos os alunos do ensino fundamental da rede pública, e a solução encontrada foi excluir do programa a grande maioria das escolas municipais.

As mudanças continuaram no ano de 1983 quando, em substituição à FENAME, foi criada a Fundação de Assistência ao Estudante (FAE), que incorporou 
vários programas de assistência do governo, incluindo o PLIDEF. Houve críticas a essa centralização da política assistencialista do governo e, conforme Freitag et.al. (1989) dentre as denúncias estavam a não distribuição dos livros didáticos nos prazos estabelecidos, a pressão política das editoras e o autoritarismo na escolha dos livros. Já nesta época propôs-se a participação dos professores na escolha dos livros e a ampliação do programa, com a inclusão das demais séries do ensino fundamental. É interessante observar que alguns estados já ofereciam aos seus professores a possibilidade de escolha de seus livros didáticos.

O atual Programa Nacional do Livro Didático (PNLD) veio substituir o PLIDEF em 1985, com a edição do decreto $n^{\circ}$ 91.542, de 19/8/85. Ele instituiu alterações significativas, especialmente nos seguintes pontos (FNDE, 2008; CASSIANO, 2004):

-garantia do critério de escolha do livro pelos professores;

-reutilização do livro por outros alunos em anos posteriores, tendo como conseqüência a eliminação do livro descartável;

-aperfeiçoamento das especificações técnicas para sua produção, visando maior durabilidade e possibilitando a implantação de bancos de livros didáticos;

-extensão da oferta aos alunos de todas as séries do ensino fundamental das escolas públicas e comunitárias;

•aquisição com recursos do governo federal, com o fim da participação financeira dos estados, com distribuição gratuita às escolas públicas.

Das inúmeras formas experimentadas pelos governantes para levar o livro didático à escola durante 67 anos (1929-1996), só com a extinção da FAE, em 1997, e com a transferência integral da política de execução do PNLD para o FNDE é que se iniciou uma produção e distribuição contínua e massiva de livros didáticos.

O PNLD tem como foco o ensino fundamental público, incluindo as classes de alfabetização infantil, e assegura a gratuidade dos livros. De acordo com o programa cada aluno tem direito a um exemplar das disciplinas de língua portuguesa, matemática, ciências, história e geografia, que serão estudadas durante o ano letivo. Aos estudantes do primeiro ano é destinada também uma cartilha de alfabetização.

O processo de avaliação pedagógica dos livros inscritos para o PNLD, como é aplicado hoje, foi iniciado em 1996 e passou por vários aperfeiçoamentos. Atualmente a síntese da avaliação pedagógica pela qual passam os livros e as coleções distribuídas 
pelo Ministério da Educação é apresentada no Guia do Livro Didático, distribuído às escolas e também disponível on-line.

A escolha dos livros é feita pelos professores das escolas públicas de todo o país, por meio do Guia do Livro Didático, onde têm a oportunidade de escolher os livros de sua preferência para serem trabalhados pelo período de três anos, sendo que o livro escolhido só poderá ser substituído por outro título no próximo PNLD. São escolhidas duas opções de títulos por disciplina e, se a primeira não conseguir ser negociada com os detentores dos direitos autorais e editores, a segunda passa a valer. Os professores de uma mesma disciplina precisam chegar a um consenso sobre a escolha do livro pois a mesma obra valerá para toda a escola.

Além do PNLD, o governo federal executa outros dois programas relacionados ao livro didático para prover as escolas das redes federal, estadual e municipal e as entidades parceiras do programa Brasil Alfabetizado: o Programa Nacional do Livro Didático para o Ensino Médio (PNLEM) criado em 2004 e o Programa Nacional do Livro Didático para a Alfabetização de Jovens e Adultos (PNLA) criado em 2007.

Os portadores de necessidades especiais são atendidos por meio do Programa Nacional do Livro Didático em Braille. Neste programa, os estudantes cegos ou com deficiência visual, do ensino fundamental das escolas públicas e escolas especializadas sem fins lucrativos começaram a ser beneficiados, de forma gradativa, com exemplares em Braille. Aos alunos com surdez das escolas de ensino fundamental e médio foi realizada a compra e distribuição, no ano de 2007, de dicionários trilíngües (português, inglês e libras). Além disso, aos alunos com surdez de $1^{\mathrm{a}}$ a $4^{\mathrm{a}}$ série, foram destinados cartilha e livro de língua portuguesa em libras e em CD-rom (FNDE, 2008).

\section{Evolução do aspecto visual do livro didático}

Desde seu início o livro didático trouxe uma ambigüidade em relação ao seu público. A figura central era a do professor, porém a partir da segunda metade do século XIX passou a se tornar mais claro que o livro didático não era um material de uso exclusivo deste, para transcrever ou ditar. Observou-se que o livro precisava ir diretamente para as mãos dos alunos. Esta mudança de perspectiva, passar a ver o aluno como consumidor direto do livro, sinalizou tanto para autores quanto editores, que era necessário modificar o produto para atender novas exigências, transformando e aperfeiçoando sua linguagem. Neste sentido, as ilustrações começaram a se tornar uma 
necessidade, assim como surgiram novos gêneros didáticos, como os livros de leitura e os livros de lições. (BITTENCOURT, 2004).

O manual escolar iniciou sua transformação em livro didático justamente a partir da década de 1960, quando as características do livro foram se adaptando à nova realidade escolar, com a democratização do ensino. Até este período estes livros sofreram poucas alterações e permaneceram muito tempo no mercado. Não eram o foco principal dos editores, nem tampouco possuíam uma linguagem de acordo com as faixas etárias às quais se destinavam. Alguns sinais mais visíveis desta transformação foram a mudança do formato que, de $14 \times 18 \mathrm{~cm}$ passou a $21 \times 28 \mathrm{~cm}$, e o aspecto visual das capas que, de austeras e rígidas passaram a oferecer um visual mais direcionado ao público escolar, com ilustrações e imagens.

Um ponto importante para a questão da mudança da qualidade do livro foi a substituição do livro descartável para o durável, introduzido pelo PNLD em 1985. O livro descartável era produzido para ser usado pelo período letivo de um ano e, por este motivo utilizava-se papel de baixa qualidade, a fim de reduzir custos e aumentar as tiragens, o que prejudicava todo o projeto gráfico. Este tipo de livro caracterizava-se por apresentar o conteúdo curricular seguido de exercícios e de atividades que deviam ser realizadas pelo estudante diretamente nas páginas do livro, como desenhos, pinturas e colagens.

Diante do papel que o livro didático ocupava no processo escolar no fim da década de 1990, o governo brasileiro, na posição de maior comprador deste tipo de livro, iniciou um processo de avaliação que ocasionou diversas melhorias nas coleções didáticas de todas as áreas disciplinares, incluindo o apuro da qualidade gráfica e de impressão, e da linguagem e conteúdo utilizados pelos autores. Segundo Gatti Júnior (2004) os livros didáticos destinados ao ensino fundamental começaram a ser impressos a quatro cores somente neste período, porém os destinados ao ensino médio, salvo exceções, ainda eram impressos em duas cores.

Hoje as editoras brasileiras já possuem a experiência de que um trabalho gráfico de má qualidade pode comprometer o sucesso de uma coleção. Em se tratando de livros didáticos a qualidade física e visual do livro é analisada em dois momentos durante a seleção das obras pelo PNLD. O primeiro ocorre logo após a inscrição das obras pelas editoras, onde é realizada uma avaliação pelo Instituto de Pesquisas Tecnológicas do Estado de São Paulo (IPT) a fim de verificar se as obras apresentadas se enquadram nas exigências técnicas e físicas do edital. Elas devem ser produzidas conforme 
especificações técnicas mínimas para produção dos livros definidas pelo MEC e FNDE. Entre os itens que devem obedecer aos padrões estabelecidos estão o formato, o papel da capa e do miolo e o acabamento. A segunda avaliação ocorre após a produção dos livros pelas editoras, quando novamente o IPT coleta amostras e analisa as características físicas dos livros de acordo com especificações da Associação Brasileira de Normas Técnicas (ABNT), normas ISO e manuais de procedimentos de ensaio préelaborados.

De acordo com um artigo do pesquisador francês Alain Choppin, no qual faz um balanço das pesquisas sobre a história do livro didático, as análises sobre estes ficam tradicionalmente restritas ao texto, mesmo considerando que desde o final do século passado a parte do livro destinada à iconografia tenha evoluído bastante. Apenas no fim dos anos 1980 o livro didático deixou de ser considerado como um texto onde as ilustrações serviam como acessórios e enfeites, e começou a ser levada em conta a articulação semântica que une o texto e a imagem. Além disso, há também a necessidade de se pesquisar as características da forma dos livros didáticos. Sobre isto o pesquisador afirma que

A organização interna dos livros e sua divisão em partes, capítulos, parágrafos, as diferenciações tipográficas (fonte, corpo de texto, grifos, tipo de papel, bordas, cores, etc.) e suas variações, a distribuição e a disposição espacial dos diversos elementos textuais ou icônicos no interior de uma página (ou de uma página dupla) ou de um livro só foram objeto, segundo uma perspectiva histórica, de bem poucos estudos, apesar dessas configurações serem bastante específicas do livro didático. Com efeito, a tipografia e a paginação fazem parte do discurso didático de um livro usado em sala de aula tanto quanto o texto ou as ilustrações (CHOPPIN, 2004, p. $559)$.

\section{Considerações Finais}

Por muito tempo, o texto escrito, o conteúdo, foi o mais importante e valorizado na hora de se produzir um livro, e as imagens desempenhavam um papel secundário ou simplesmente decorativo. Contudo hoje, a imagem passou a ser valorizada e seu papel é visto como menos decorativo e mais ilustrativo, no sentido de apoiar e complementar o conteúdo textual (COUTINHO; FREIRE, 2006). A relação entre imagem e texto, formas, cores, enfim toda comunicação visual do impresso, necessita ser observada, especialmente em relação à sua capacidade mediadora.

Com os comitês de avaliação editoriais, os livros estão ganhando em conteúdo, já que estão sendo avaliados pelos pares de seus autores, porém não são avaliados em 
termos de linguagem visual. Aprofundar a questão da mediação que a comunicação visual do livro promove também levanta pontos como a apresentação do conteúdo de forma criativa, organizada e interessante, o estímulo ao estudo e a compreensão do conteúdo. A criança pode adquirir assim, de maneira mais eficiente, satisfatória e principalmente prazerosa, os conhecimentos escolares, facilitando a construção do conhecimento e ampliando o potencial pedagógico do livro.

\section{Referências}

BITTENCOURT, Circe M. F. Autores e editores de compêndios e livros de leitura (1810-1910). In: Revista Educação e Pesquisa, vol.30, n.3, São Paulo, p. 475-491, Set./Dez. 2004.

CASSIANO, Célia C. F. Mercado de livro didático no Brasil. [on-line] I Seminário Brasileiro sobre Livro e História Editorial. Universidade Federal Fluminense, Rio de Janeiro, 2004. Disponível em: <http://www.livroehistoriaeditorial.pro.br/pdf/celia cristinacassiano.pdf>. Acesso em 20 fev. 2008.

CHOPPIN, Alain. História dos livros e das edições didáticas: sobre o estado da arte. [on-line] Revista Educação e Pesquisa, São Paulo, v.30, n.3, p. 549-566, set./dez. 2004. Tradução de Maria Adriana C. Cappello. Disponível em:

<http://www.scielo.br/pdf/ep/v30n3/a12v30n3.pdf>. Acesso em: 20 fev. 2008.

COUTINHO, Solange G.; FREIRE, Verônica E. C. Design para Educação: uma avaliação do uso da imagem nos livros infantis de língua portuguesa. In: Anais do $\mathbf{1 5}^{\circ}$ Encontro Nacional da Anpap. Universidade de Salvador: UNIFACS, Salvador, 2006. p.245-254.

FARBIARZ, Jackeline Lima, FARBIARZ, Alexandre. O designer como mediador na interação entre o livro e o leitor. In: Anais do P\&D Design 2004. $6^{\circ}$ Congresso Brasileiro de Pesquisa e Desenvolvimento em Design, 2004, Fundação Armando Alvares Penteado: São Paulo, 2004.

FNDE - Fundo Nacional de Desenvolvimento da Educação. Ministério da Educação. Disponível em: 〈http://www.fnde.gov.br/home/index.jsp?arquivo=livro_didatico.html $>$. Acesso em: 20 fev. 2008.

FREITAG, Bárbara et alii. O livro didático em questão. 3. ed. São Paulo: Cortez, 1997.

GATTI JÚNIOR, Décio. A escrita escolar da história: livro didático e ensino no Brasil. Bauru, SP: Edusc; Uberlândia, MG: Edufu, 2004.

STRAY, Chris. Quia Nominor Leo: Vers une sociologie historique du manuel. In: CHOPPIN, Alain (org.) Histoire de l'éducation. $\mathrm{n}^{\circ} 58$ (numéro spécial). Manuels scolaires, États et sociétés. XIXe-XXe siècles, Ed. INRP, 1993. 